\title{
Light-Driven Chemical Looping for Ammonia
}

\section{Synthesis}

Dayne F. Swearer, ${ }^{1,3}$ Nicola R. Knowles, ${ }^{1,3}$ Henry O. Everitt, ${ }^{2,4}$ Naomi J. Halas, ${ }^{1,2,3, *}$

${ }^{1}$ Department of Chemistry, ${ }^{2}$ Department of Electrical and Computer Engineering, ${ }^{3}$ Laboratory for Nanophotonics, Rice University, Houston, Texas 77005, United States, ${ }^{4}$ U.S. Army, Combat Capabilities Development Command, Aviation \& Missile Center, Redstone Arsenal, AL 35898, United States

Supplementary Information 


\section{Table of Contents}

\section{Materials and Methods}
a. Materials
b. $\mathrm{TiN} / \mathrm{MgO}$ nanopowder preparation
c. Diffuse Reflectance characterization
d. X-Ray Photoelectron Spectroscopy (XPS)
e. In situ rotational spectroscopy
f. Photothermal Heating Measurements
g. Electron Microscopy
h. Powder X-ray Diffraction
i. Surface Area Analysis
j. Solar-to-chemical conversion efficiency

\section{Supplementary Figures}

a. Figure $\mathrm{S} 1$ - XPS of pristine TiN nanoparticles

b. Figure $\mathrm{S} 2$ - XPS of pristine $\mathrm{MgO}$ nanopowder

c. Figure $\mathrm{S} 3$ - Diffuse reflectance of $\mathrm{TiN} / \mathrm{MgO}$ nanopowder

d. Figure S4 - Diagram of in situ reaction chamber and rotational spectrometer

e. Figure S5 - Calibration curve for ${ }^{12} \mathrm{CO}$

f. Figure $\mathrm{S} 6-\mathrm{MgO}$ reduction with ${ }^{13} \mathrm{CH}_{4}$.

g. Figure $\mathrm{S} 7$ - Contributions from adventitious carbon and ${ }^{13} \mathrm{CH}_{4}$

h. Figure $\mathrm{S} 8$ - Laser-induced heating of $\mathrm{MgO} \& \mathrm{TiN} / \mathrm{MgO} \mathrm{NP}$

i. Figure S9 - High-resolution X-ray photoelectron spectra of 20 wt \% TiN/MgO

j. Figure S10 - Temporal evolution of ammonia isotopologues

k. Figure $\mathrm{S} 11$ - Monitoring $\mathrm{MgO}$ reduction without inclusion of TiN

1. Figure $\mathrm{S} 12$ - Hydrolysis of $\mathrm{MgO}$ without $\mathrm{TiN}$

m. Figure S13 - Carbon monoxide evolution from pure TiN nanoparticles. 
n. Figure S14 - Hydrolysis of pure TiN Nanoparticles.

o. Figure $\mathrm{S} 15$ - Band Alignment of $\mathrm{TiN}$ and $\mathrm{MgO}$

p. Figure $\mathrm{S} 16-\mathrm{N}_{2}$ uptake capacity and surface area measurements.

q. Figure S17 - Powder X-ray diffraction characterization

\section{Supplementary Tables}

a. Table SI - Curve fitting of XPS Spectra Pre-Nitridation

b. Table SII - Curve fitting of XPS Spectra Post-Nitridation

\section{Supplementary References}




\section{Materials and Methods}

\section{a. Materials}

- All components of the plasmonic catalyst are commercially available. Titanium Nitride nanoparticles [TiN, 99.2+\%, 20nm, cubic] were purchased from US Research Nanomaterials, Inc. Magnesium oxide nanopowder $[\mathrm{MgO}, \leq 50 \mathrm{~nm}$ particle size (BET), \#549649], isotopically labeled methane $\left({ }^{13} \mathrm{CH}_{4}, \geq 99.5 \%{ }^{13} \mathrm{C}\right.$, \#603376) and deuterium oxide $\left(\mathrm{D}_{2} \mathrm{O}, 99.9 \% \mathrm{D}, \# 151882\right)$ were purchased from Sigma-Aldrich. Nitrogen $\left({ }^{14} \mathrm{~N}_{2}, 99.999 \%\right)$ was purchased from Airgas. All materials were used as received without further purification.

\section{b. TiN/MgO nanopowder preparation}

- All combinations of TiN and $\mathrm{MgO}$ were made on weight percentage (wt\%) basis with respect to the TiN. For example, to prepare a $20 \mathrm{wt} \% \mathrm{TiN} / \mathrm{MgO}$ nanopowder a nominal mass of $20 \mathrm{mg}$ of TiN was weighed out on an analytical balance and set aside. Next, a nominal mass of $100 \mathrm{mg} \mathrm{MgO}$ nanopowder was weighed out and set aside. Both TiN and $\mathrm{MgO}$ were then combined in a mortar and pestle and ground into a fine powder until the color was uniform, which could be described as a dark grey or black. The $20 \mathrm{wt} \% \mathrm{TiN} / \mathrm{MgO}$ was then removed from the mortar and placed into a $2 \mathrm{~mL}$ centrifuge tube until further use.

\section{c. Diffuse Reflectance characterization}

- Optical characterization of the TiN/MgO NP was performed on a Cary 5000 UV/Vis/NIR (Agilent) equipped with a Praying Mantis ${ }^{\mathrm{TM}}$ diffuse reflectance accessory (Harrick Scientific Products, Inc.). Background subtraction was taken directly from a packed bed of MgO (Sigma-Aldrich, \#549649), with simultaneous adjustments of reflecting mirrors to maximize total reflectance of $\mathrm{MgO}$. For optical measurements, $20 \mathrm{wt} \% \mathrm{TiN} / \mathrm{MgO}$ was diluted with additional $\mathrm{MgO}$ nanopowder until the final concentration of TiN was between 1-3\% to minimize absorption and measure specular reflectance. All scans were made between $400-1200 \mathrm{~nm}$ at a rate of $600 \mathrm{~nm} / \mathrm{min}$.

\section{d. X-Ray Photoelectron Spectroscopy (XPS)}

- All XPS measurements were made with a PHI Quantera X-ray Photoelectron spectrometer using a monochromated $\mathrm{Mg} \mathrm{K \alpha}$ source $(1253.6 \mathrm{eV})$. The X-ray spot had a diameter of $200 \mu \mathrm{m}$ and was operated at a power of $50 \mathrm{~W}$ at $15 \mathrm{kV}$. Instrumental base pressure was kept below $5 \times 10^{-9}$ mbar during the measurements presented here. All survey scans were performed between $0 \mathrm{eV}$ and $1100 \mathrm{eV}$ with an energy step width of $\Delta \mathrm{E}=0.5 \mathrm{eV}$. Detailed scans were recorded from 449 - 469 
$\mathrm{eV}$ for Ti 2p, $390-405 \mathrm{eV}$ from N 1s, $523-538 \mathrm{eV}$ for $\mathrm{O} 1 \mathrm{~s}$, and $80-95 \mathrm{eV}$ for $\mathrm{Mg}$ 2s. The number of sweeps for each spectral region were 50, and data were collected with a pass energy of $\mathrm{E}_{\mathrm{p}}=26.00 \mathrm{eV}$ with an energy step width of $\Delta \mathrm{E}=$ $0.1 \mathrm{eV}$ and a $20 \mathrm{~ms}$ time per step. Argon sputtering was used to clean the surface of relevant collection areas gently prior to final data acquisition. Post-nitridation TiN/MgO was rapidly transferred from the in situ reaction chamber to the XPS, on the order of minutes, to minimize hydrolysis of any fresh $\mathrm{Mg}_{3} \mathrm{~N}_{2}$ from laboratory humidity.

\section{e. In situ rotational spectroscopy}

- Approximately $20 \mathrm{mg}$ of TiN/MgO NP was packed into a small cup that held an 8 $\mathrm{mm}$ inner diameter stainless steel ring. The TiN/MgO nanopowder was packed into the stainless steel ring with a stainless steel rod of equivalent outer diameter by hand until a porous, yet sturdy 1-2 mm thick pellet was formed. The ring containing the TiN/MgO NP was secured into a stainless steel block using a small stainless steel hex set screw. Similarly, the block was mounted to a copper rod of a customized electric feedthrough 2-3/4" ConFlat flange (Kurt J. Lesker Company) with a stainless steel set screw. Similarly, on the underside of the stainless steel block, an ultra-high vacuum heater cartridge (Heat Wave Labs, Inc., standard series cartridge heater, \#101128) was secured with stainless steel set screws and connected to copper wire leads routed through the feedthrough flange. An external power source was connected to the external copper leads to heat the catalyst. The internal reaction temperature was measured using a K-type thermocouple as close to the nanopowder surface as possible $(\sim 1 \mathrm{~mm})$ also routed through the feedthrough flange. The feedthrough flange was connected at the bottom port of the 5-way stainless steel cross (Main Text; Fig. 2). Quartz windows were used to seal off the top and side ports for optical and microwave radiation, respectively.

Before any chemical looping experiments, the entire reaction chamber, including the vacuum and gas manifolds, and bellows connected the vacuum system (Pfeiffer Vacuum HiCube 300 eco turbo pumping station) were baked during the evacuation. External heat was applied using ultra-high temperature heating tape (Omega Engineering, HTC-120) and internally using the heater cartridge onto which the TiN/MgO NP was mounted. Typical bake outs lasted 12 hours, and no experiments were performed until the cold reaction chamber base pressure was $\leq 5 \times 10^{-6}$ Torr as measured by an ion gauge.

Gas delivery was performed in an isolated section of the manifold (Fig S4B). Both

${ }^{13} \mathrm{CH}_{4}$ and $\mathrm{N}_{2}$ tanks were connected to the vacuum system with a 2-3/4" ConFlat to 1/8" Swagelok adaptor fitting (Kurt J. Lesker Company, \#F0275X2SWG). A 1/4" stainless steel cold finger, with a needle valve on the open end, was loaded with $\mathrm{D}_{2} \mathrm{O}$, and connected to the vacuum system with a 2-3/4" ConFlat to 1/4" Swagelok adaptor fitting (Kurt J. Lesker Company, \#F0275X4SWG). For each reactant, a series of 2-3 valves were placed in line to isolate small volumes prior to 
introduction to the manifold system and reaction chamber. Pressures were monitored from 0-760 Torr with a convection gauge (Kurt J. Lesker Company, 275i Series Gauge), and between 0-1000 mTorr and 0-100 mTorr with two MKS Baratron ${ }^{\circledR}$ capacitance manometers located in the gas delivery and reaction chamber subsections, respectively. Prior to delivery of $\mathrm{D}_{2} \mathrm{O}$ into the reaction chamber, a freeze-pump-thaw method was implemented using liquid nitrogen to remove small gas molecules $\left(\mathrm{N}_{2}, \mathrm{O}_{2}, \mathrm{CO}_{2}\right.$, etc.) that had leaked into the cold finger and to control delivery of low-pressures. All gases were delivered in succession. ${ }^{13} \mathrm{CH}_{4}$ was introduced to the reaction chamber during the course of a reaction, evacuated, and refilled with $\mathrm{N}_{2}$. Likewise, after reaction (2) $\mathrm{N}_{2}$ was evacuated completely from the chamber prior to introduction of $\mathrm{D}_{2} \mathrm{O}$.

Data collection was automated for rotational spectra, source power, and chamber pressure using LabView software. The microwave synthesizer was a narrowband tunable source followed by three-frequency multipliers (Virginia Dioides, Inc.; WR3.4x3) to produce radiation in the frequency band from 220-330 GHz. The signal was detected by a zero-biased Schottky diode (Virginia Diodes, Inc.; WR3.4ZBD) operating in this band. The signal was passed to a transimpedance amplifier (Perry Instruments), then a low noise preamplifier (SRS SR560) and a lock-in amplifier (AMETEK Lock-in Amplifier 7270 DSP). The output is digitized (National Instruments; USB6251 M Series).

Optical illumination of the TiN/MgO NP was performed at $808 \mathrm{~nm}$ from a modelocked Ti:Sapphire laser (Coherent, Chameleon Ultra II, 150 fs, $80 \mathrm{MHz}, 680-1080$ $\mathrm{nm}, \sim 10 \mathrm{~nm}$ bandwidth).

\section{f. Photothermal Heating Measurements}

- Photothermal heating measurements were performed outside of the in situ reaction chamber because the quartz optical ports did not allow the infrared camera to receive a signal. Instead, photothermal measurements were performed in a Raman high-temperature reaction chamber (Harrick Scientific Instruments, Inc.; \#HVCMRA-5) with a large $\mathrm{KBr}$ optical window (International Crystal Labs, $25 \mathrm{~mm} * 2 \mathrm{~mm}$ ) on the top. The reaction chamber was evacuated to a base pressure of 50 mTorr with a vacuum system (Pfeiffer Vacuum HiCube 300 eco turbo pumping station) and illuminated with a stationary $808 \mathrm{~nm}$ laser at $30 \mathrm{~W} / \mathrm{cm}^{2}$. Thermal measurements were acquired with a FLIR A615 Infrared camera at six frames per second.

\section{g. Electron Microscopy}

- Transmission electron micrographs were acquired on a JEOL-2100 field emission gun electron microscopy operating at $200 \mathrm{kV}$. 


\section{h. Powder X-ray Diffraction}

- Powder X-ray diffraction patterns were recorded with a Rigaku D/Max Ultima II diffractometer configured with a vertical $\theta / \theta$ goniometer using $\mathrm{Cu} \mathrm{K} \alpha$ radiation $(\lambda$ $=1.5406 \AA$ ).

\section{i. Surface Area Analysis}

- $\mathrm{N}_{2}$ adsorption studies for gas uptake capacity and surface area measurements were performed at $77 \mathrm{~K}$ up to 1 bar using a Quantachrome Autosorb-iQ automated gas sorption analyzer. All samples were dried and activated prior to the sorption measurements by heating under vacuum at $423 \mathrm{~K}$ for 2 hours.

\section{j. Solar-to-chemical (SCC) conversion efficiency}

Solar-to-chemical conversion efficiency is defined by the following equation ${ }^{1}$ :

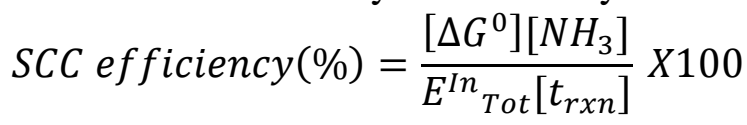

Where the free energy for $\mathrm{NH}_{3}$ formation is $339 \mathrm{~kJ} \mathrm{~mol}^{-1}$. The total chemical looping time was 14 hours, or 50,400 seconds. And the total $\mathrm{NH}_{3}$ formation was $2.338 \mathrm{E}-5$ moles with an input laser power of $0.3 \mathrm{~W}$ yields a SCC efficiency of $0.05 \%$. This calculation assumes a single ammonia isotopologue in production and neglects additional energy contributions from non-optical components of the in situ reactor/spectrometer.

\section{Supplementary Figures}

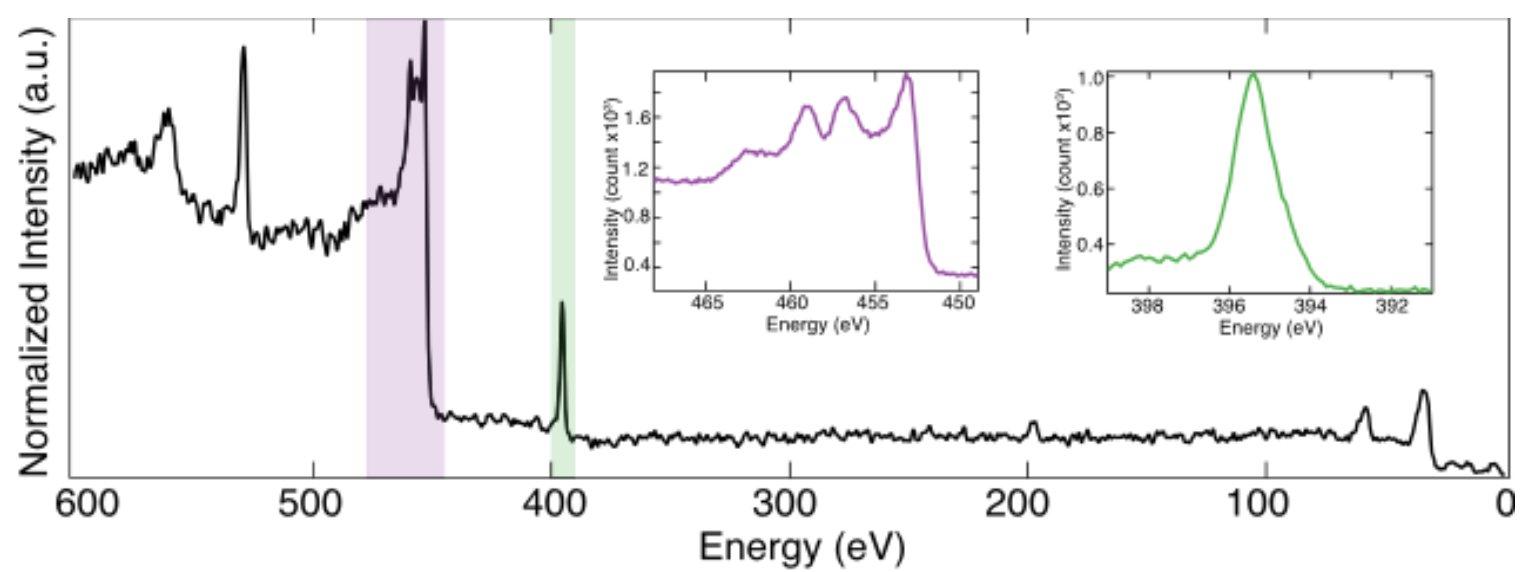

Figure S1 - X-ray photoelectron spectra of pristine TiN nanoparticles. Detailed scans of Ti 2p (449 - $469 \mathrm{eV}$; purple) and N 1s (391 - $399 \mathrm{eV}$; green) are shown as insets. Additional peak 
features in the survey scan are $\mathrm{O} 1 \mathrm{~s}(\sim 532 \mathrm{eV})$, Ti $2 \mathrm{~s}(\sim 562 \mathrm{eV}), \mathrm{Ti} 3 \mathrm{~s}(\sim 59.8 \mathrm{eV})$, and Ti 3p, $(\sim 36.6 \mathrm{eV})$.

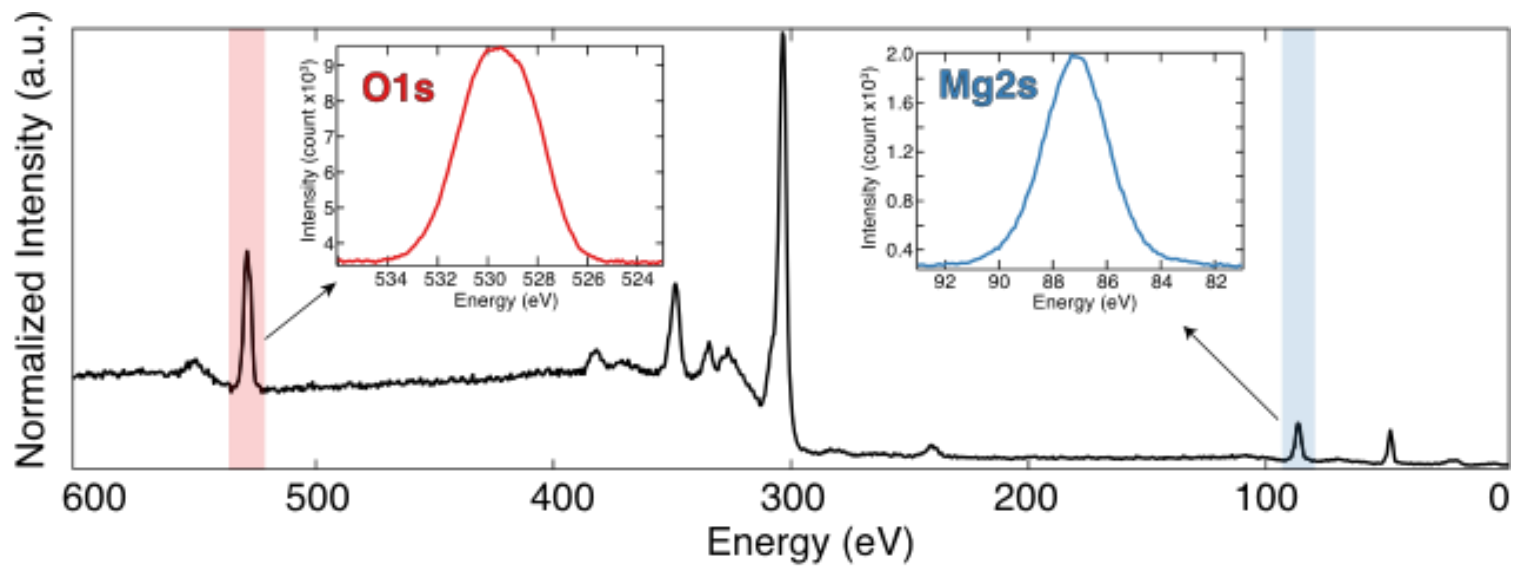

Figure S2 - X-ray photoelectron spectra of MgO nanopowder. Detailed scans of O 1s (523 $536 \mathrm{eV}$; red) and $\mathrm{Mg} 2 \mathrm{~s}(81-93 \mathrm{eV}$; blue) are shown as insets. $\mathrm{Mg} 2 \mathrm{~s}$ can be fit with a single Gaussian centered at $87.15 \mathrm{eV}$. Additional peak features in the survey scan correspond to several Mg KLL auger peaks between $300-390 \mathrm{eV}$, implanted Ar 2p ( 243 eV), and Mg 2p (49.8 eV).

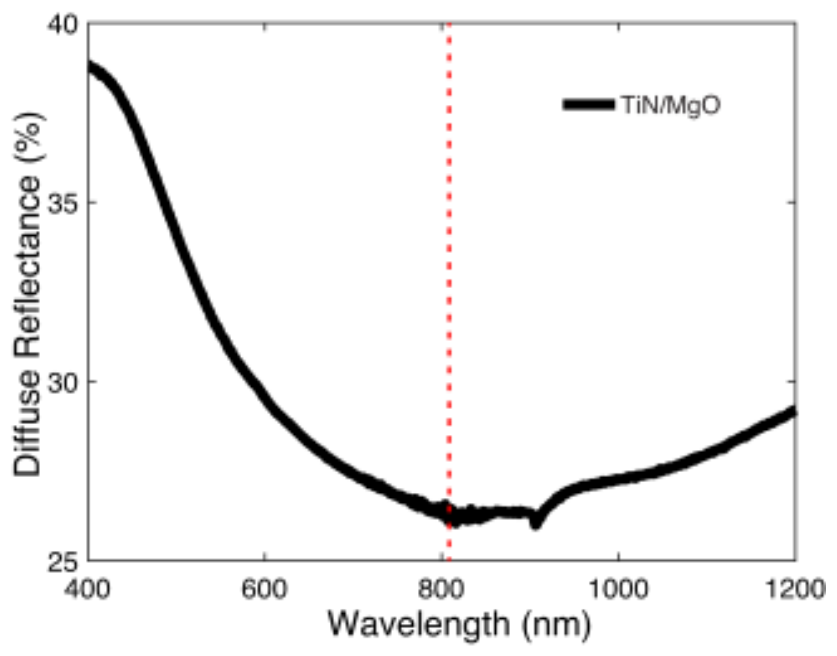

Figure S3 - Diffuse reflectance of TiN/MgO nanopowder. The red dashed line corresponds the $808 \mathrm{~nm}$ illumination wavelength from the Ti:Sapphire laser. 
A

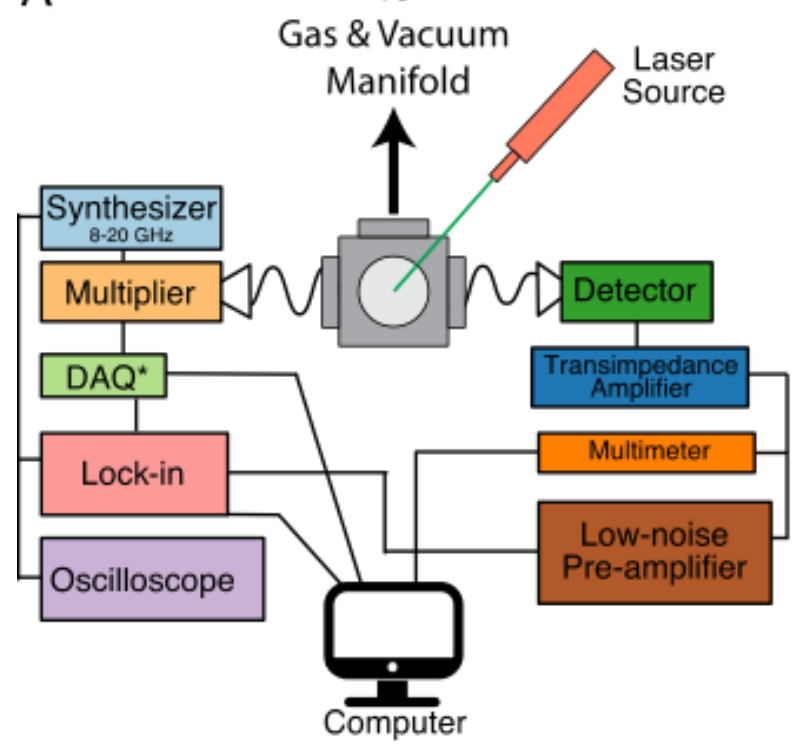

B

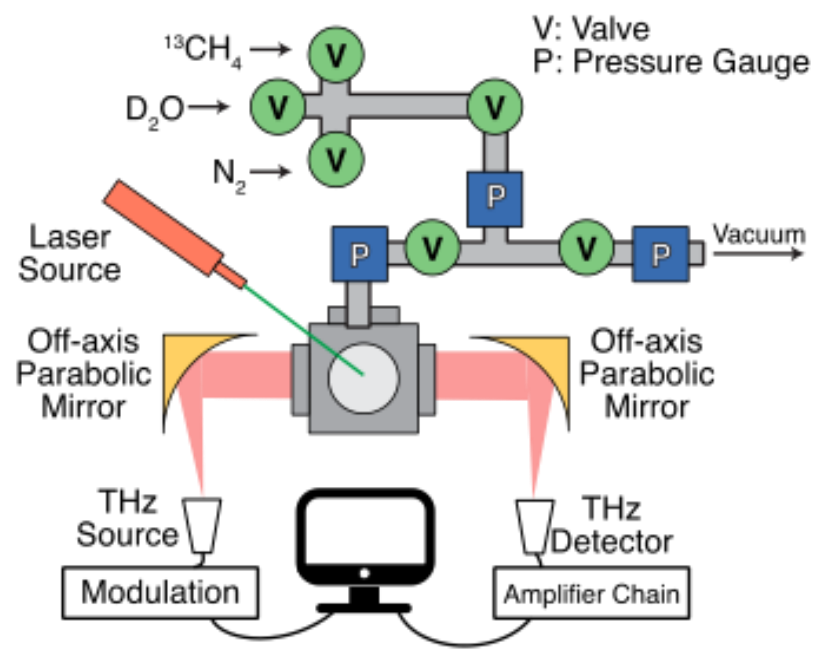

Figure S4 - Diagram of in situ reaction chamber and rotational spectrometer. (A) The block electronics diagram in place for rotational spectra data acquisition. (B) A diagram of the gas and vacuum manifold for gas delivery and chamber evacuation with respect to the chamber and data acquisition electronics.

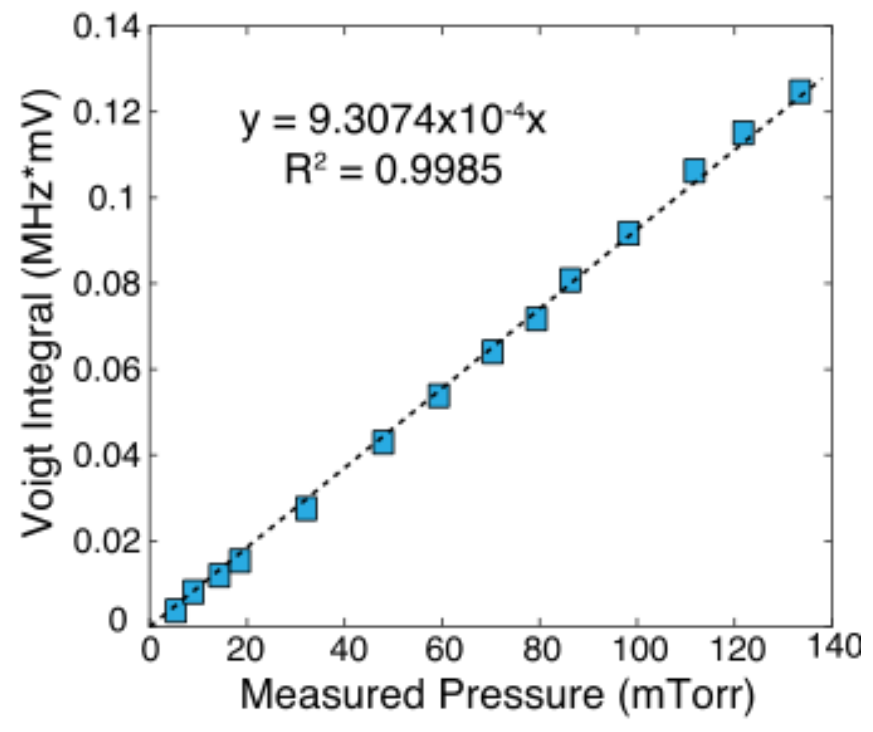

Figure S5 - Calibration curve for ${ }^{12} \mathrm{CO}$. Corresponding to the rotational transition for carbon monoxide $\mathrm{J}=1 \rightarrow 2$ at $230.5380 \mathrm{GHz}$. 


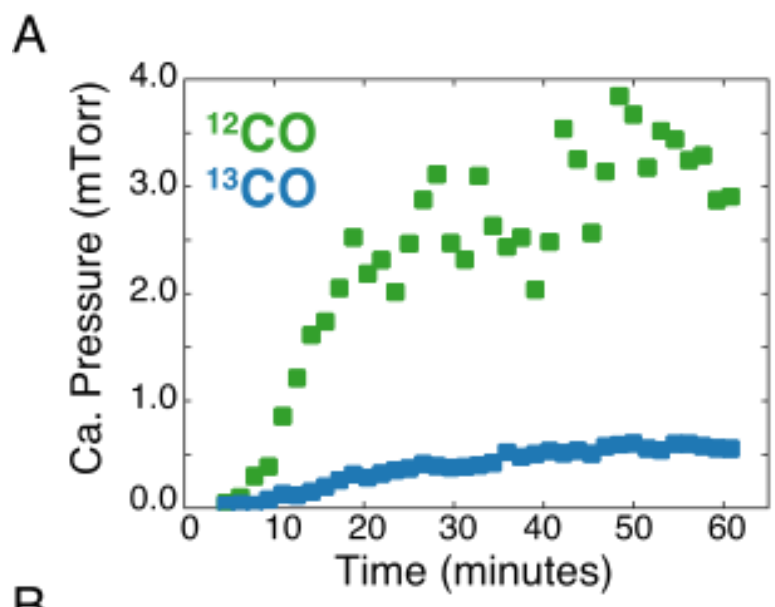

B
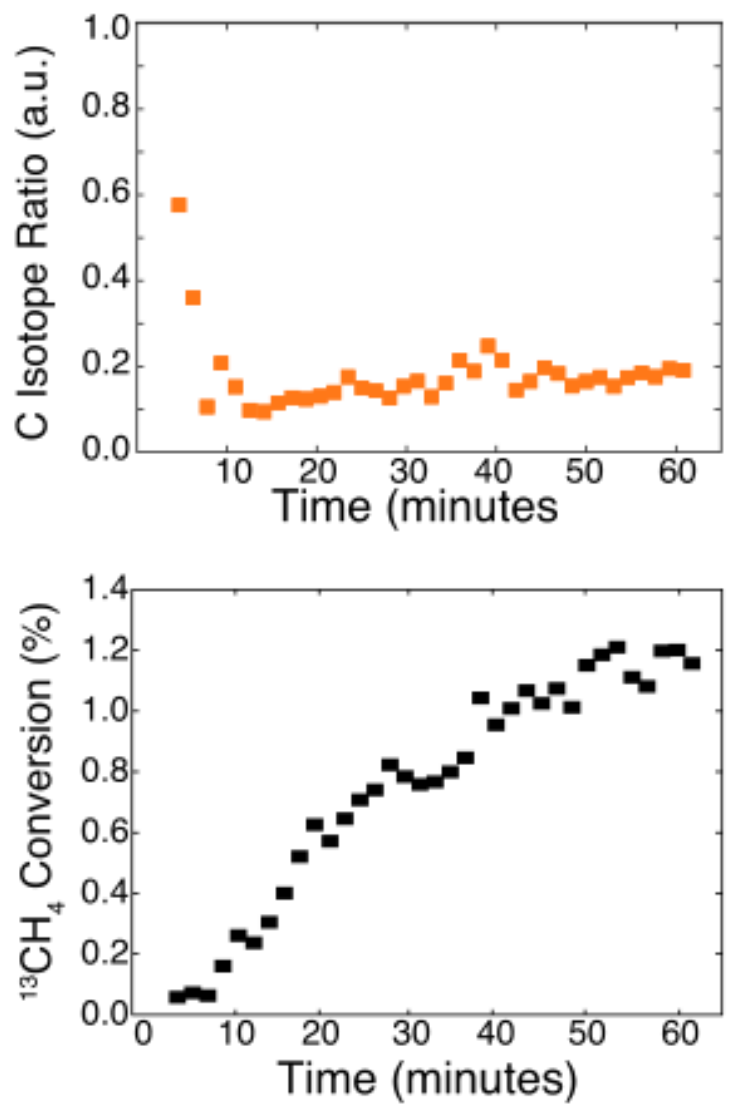

Figure S6 - MgO reduction with ${ }^{13} \mathbf{C H}_{4}$. (A) Partial pressures of carbon monoxide evolution immediately prior to the experiment in main text figure 3 . (B) Isotopic ratios of ${ }^{13} \mathrm{C}$ to ${ }^{12} \mathrm{C}$ evolved during the reaction (C) Percentage of ${ }^{13} \mathrm{CH}_{4}$ converted during the course of 60 minutes of $\mathrm{MgO}$ reduction. 
A

$$
\begin{gathered}
98.9 x+0.5 y=p\left({ }^{12} \mathrm{CO}\right) \\
1.1 x+99.5 y=p\left({ }^{13} \mathrm{CO}\right) \\
x=\text { Adventitious Carbon } \\
y={ }^{13} \mathrm{CH}_{4} \text { source }
\end{gathered}
$$

C

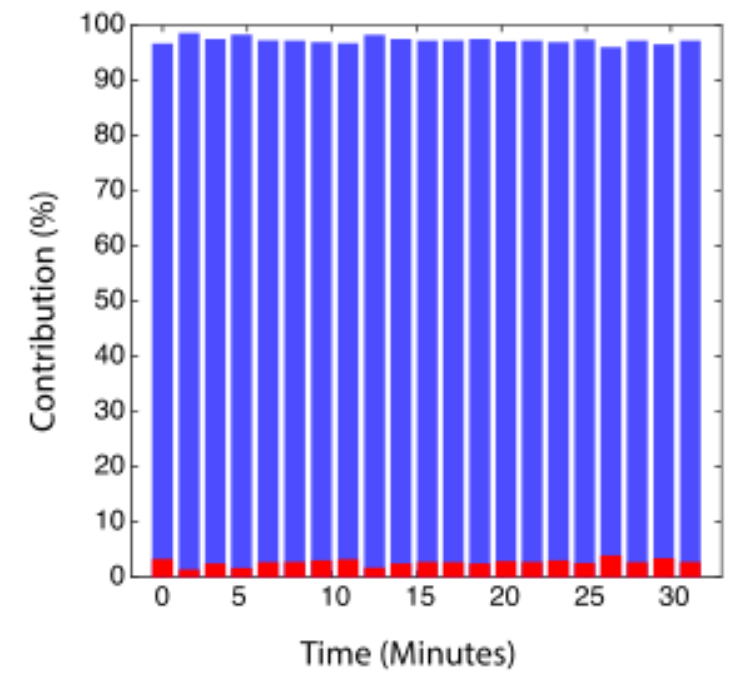

B

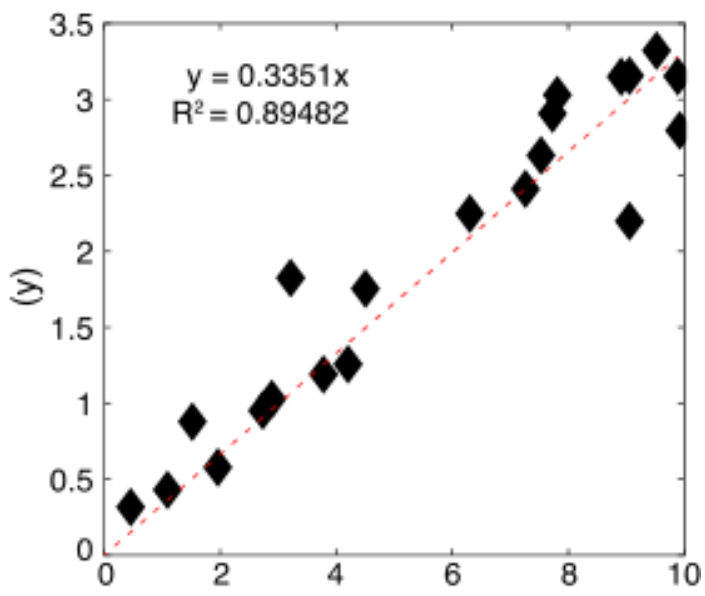

(x)

D

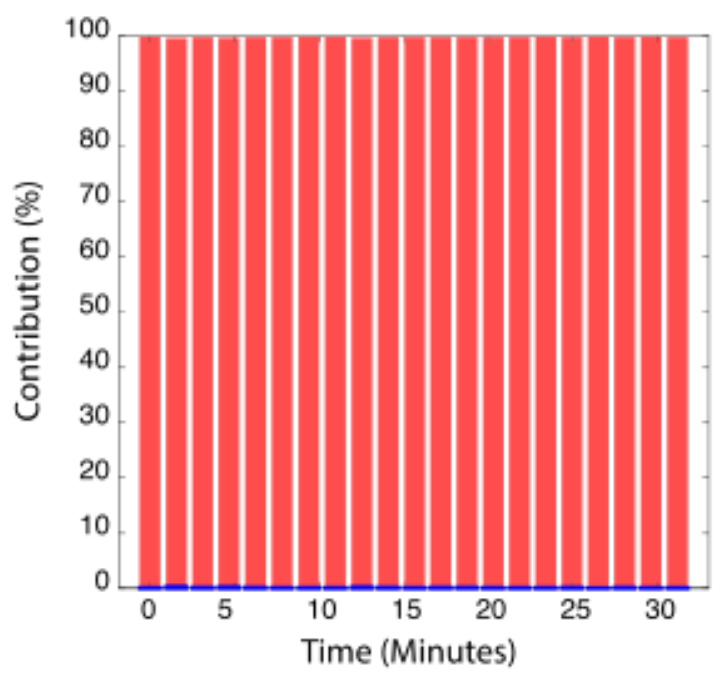

Fig S7 - Contributions from adventitious carbon and ${ }^{13} \mathrm{CH}_{4}$. (A) System of linear equations used to calculate the contributions of $\mathrm{CO}$ partial pressures, where $\mathrm{x}$ is the contribution from naturally occurring carbon and $\mathrm{y}$ is the contribution from the isotopically purified methane source. These equations were used to solve for $\mathrm{x}$ and $\mathrm{y}$ as a function of the spectroscopically measured partial pressure of ${ }^{12} \mathrm{CO}$ and ${ }^{13} \mathrm{CO}$. (B) Plot of the $\mathrm{x}$ and $\mathrm{y}$ values deduced from solving the equations in (A). (C) Contributions of ${ }^{13} \mathrm{CH}_{4}$ (blue) and adventitious carbon (red) to the overall partial pressure of ${ }^{13} \mathrm{CO}$. The contribution to the ${ }^{13} \mathrm{CO}$ signal was $97.3 \pm 0.6 \%$ derived from isotopically labeled methane. (D) The contribution of ${ }^{12} \mathrm{CO}$ partial pressure was dominated by adventitious carbon $(99.8 \pm 0.1 \%)$. This verifies that the major source of ${ }^{13} \mathrm{CO}$ is the reduction of $\mathrm{MgO}$ with ${ }^{13} \mathrm{CH}_{4}$. 


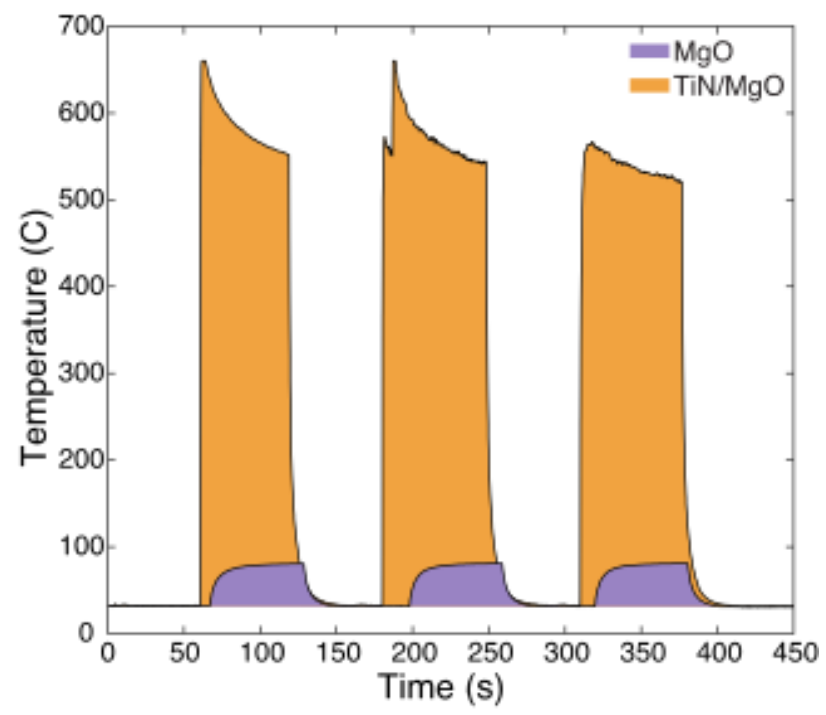

Figure S8 - Laser-induced heating of MgO \& TiN/MgO NP. 20 mg of MgO nanopowder at a base pressure of $50 \mathrm{mTorr}$ reached a temperature of $\sim 80{ }^{\circ} \mathrm{C}$ under $30 \mathrm{~W} / \mathrm{cm}^{2}$ at $808 \mathrm{~nm}$ (purple), while $20 \mathrm{wt} \% \mathrm{TiN} / \mathrm{MgO} \mathrm{NP}$ reached $\geq 550^{\circ} \mathrm{C}$ under identical illumination conditions (orange).

A
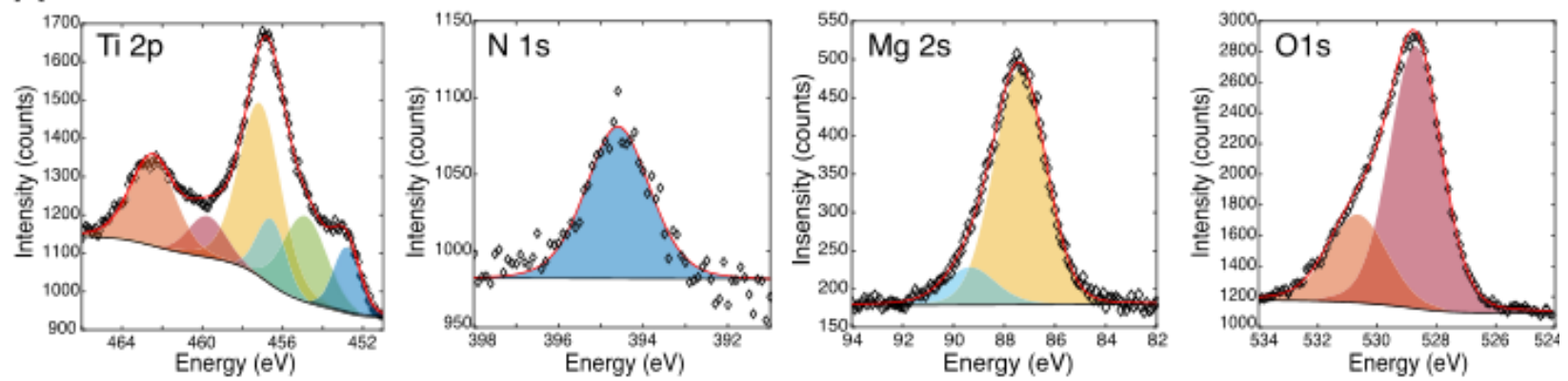

B
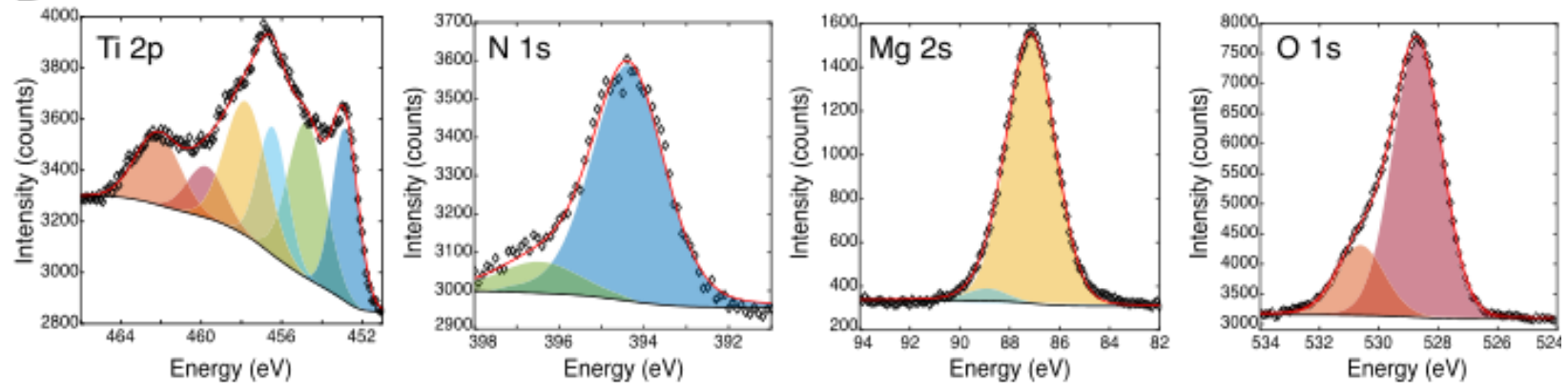

Figure S9 - High-resolution X-ray photoelectron spectra of 20 wt \% TiN/MgO NP (A) Prenitridation (B) Post-nitridation. A curve-fitting summary is provided in Tables SI and II. XPS of Ti $2 p$ pre-nitridation reveals the majority of the spectrum $(37.35 \%$ by area) is dominated by a peak at $457.12 \mathrm{eV}$, which has been suggested, belongs to an intermediate state between $\mathrm{TiN} / \mathrm{TiO}{ }_{2}{ }^{2}$ The growth of a high energy peak at $396.46 \mathrm{eV}$ post-nitridation is characteristic of magnesium nitride formation, based on ion implantation experiments. ${ }^{3}$ 


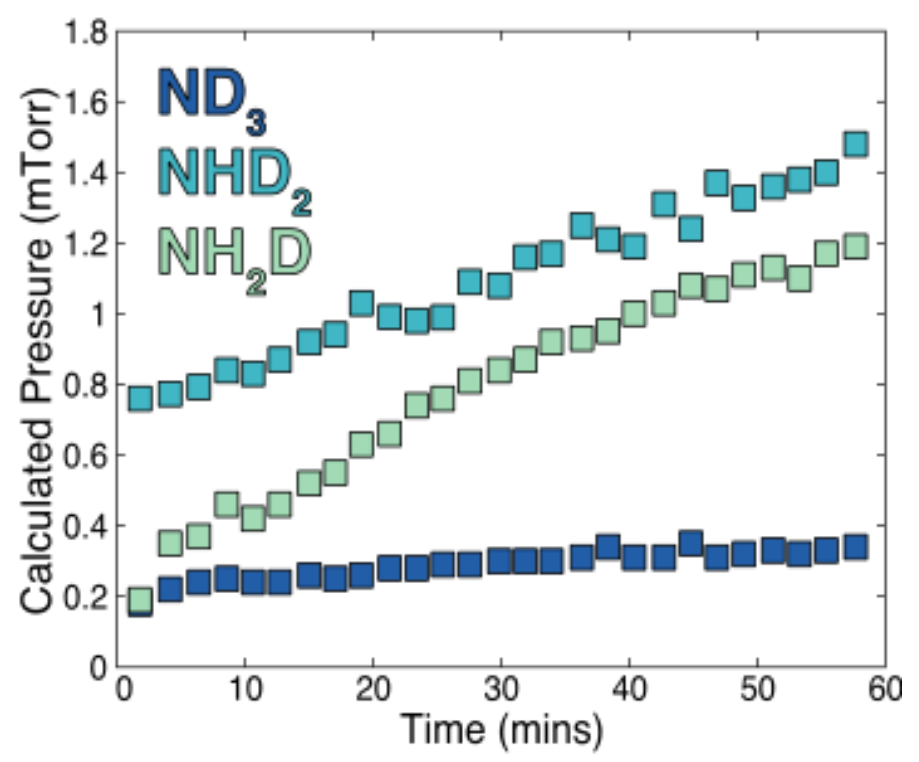

Figure S10 - Temporal evolution of ammonia isotopologues. Partial pressures were determined by integrating the frequency modulated line of each isotopologue with a single Voigt function and using the cross-calibration method with reference to the calibration of ${ }^{12} \mathrm{CO}(\mathrm{J}=1 \rightarrow 2$; Fig. S6) to determine ammonia partial pressures. 
${ }^{12} \mathrm{CO}$
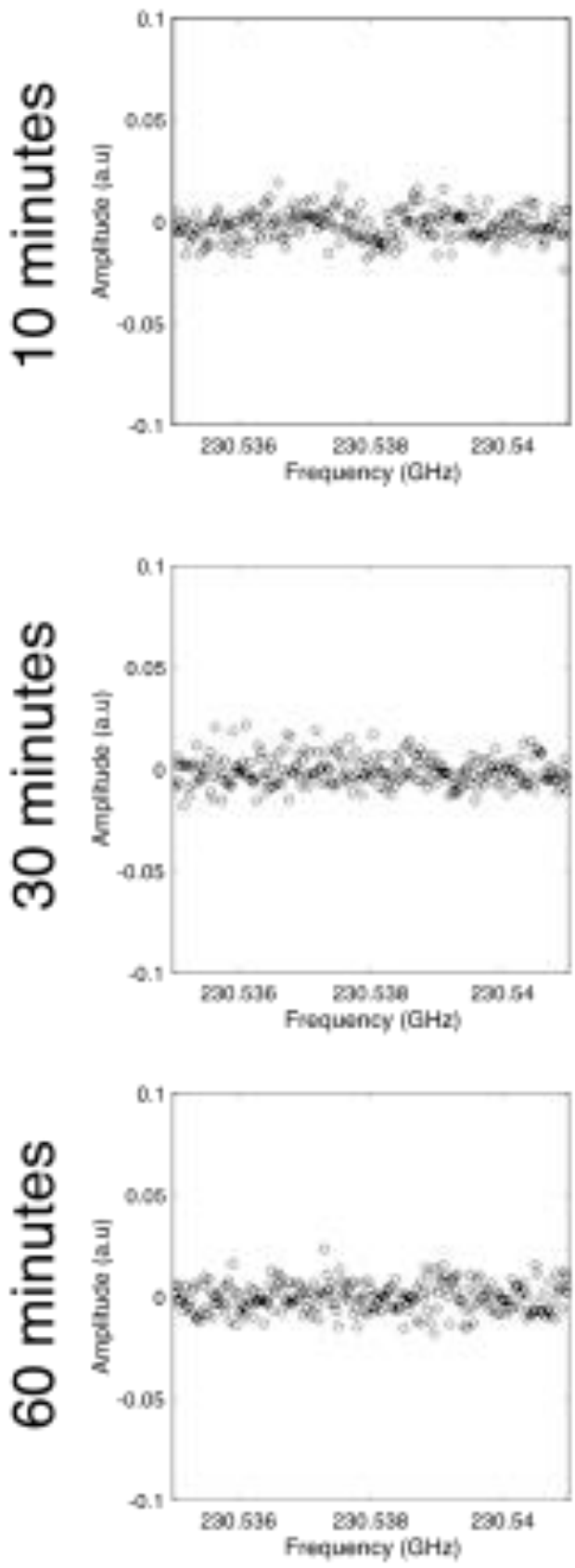

${ }^{13} \mathrm{CO}$
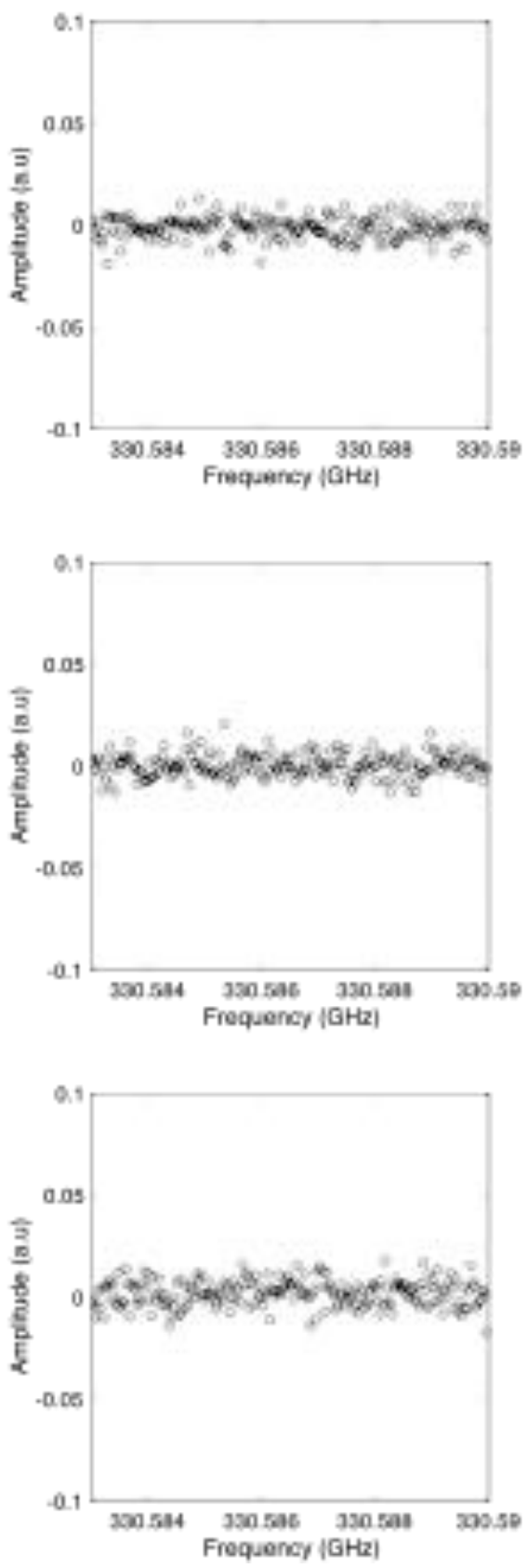

Figure S11 - Monitoring MgO reduction without inclusion of TiN. The evolution of ${ }^{12} \mathrm{CO}$ and ${ }^{13} \mathrm{CO}$ were monitored during a control experiment where pure $\mathrm{MgO}$ nanoparticles were illuminated at $808 \mathrm{~nm}$ at $30 \mathrm{~W} / \mathrm{cm}^{2}$ with a nominal pressure of $50 \mathrm{mTorr}{ }^{13} \mathrm{CH}_{4}$. Neither isotopologue was observed during 60 minutes of illumination, suggesting that photothermal heating induced by TiN nanoparticles (Fig. S8) is necessary to reduce $\mathrm{MgO}$. 
$\mathrm{ND}_{3}$
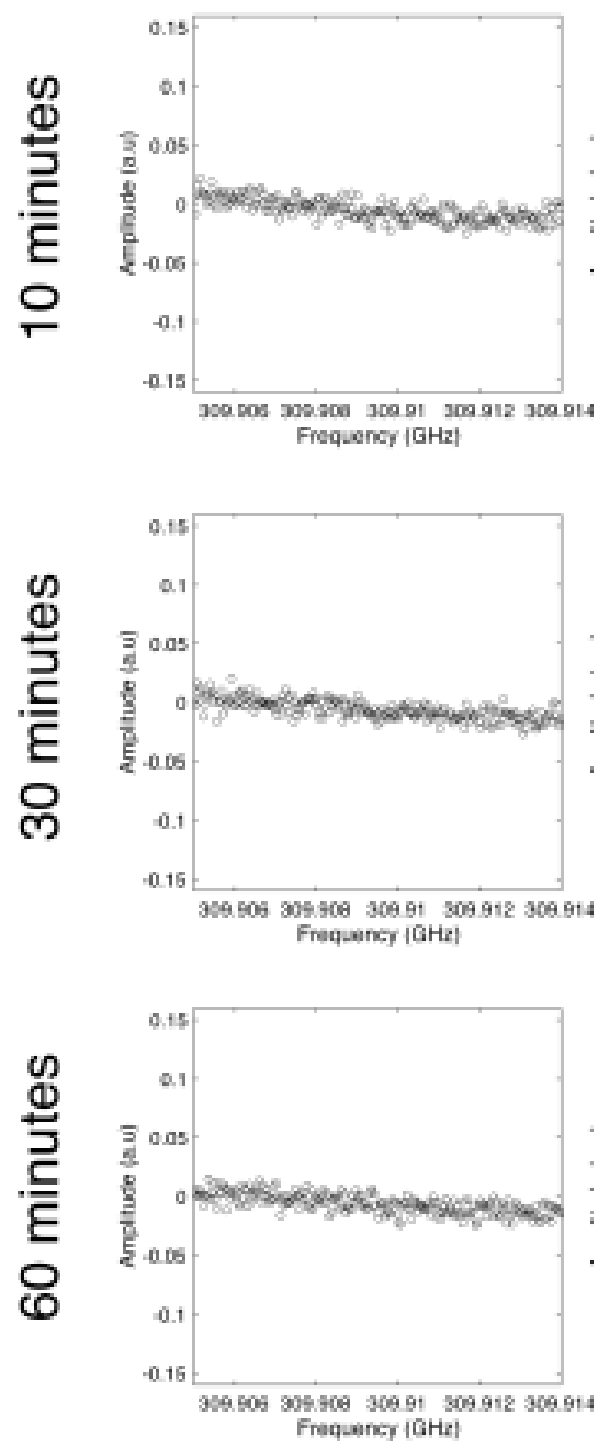

$\mathrm{NHD}_{2}$
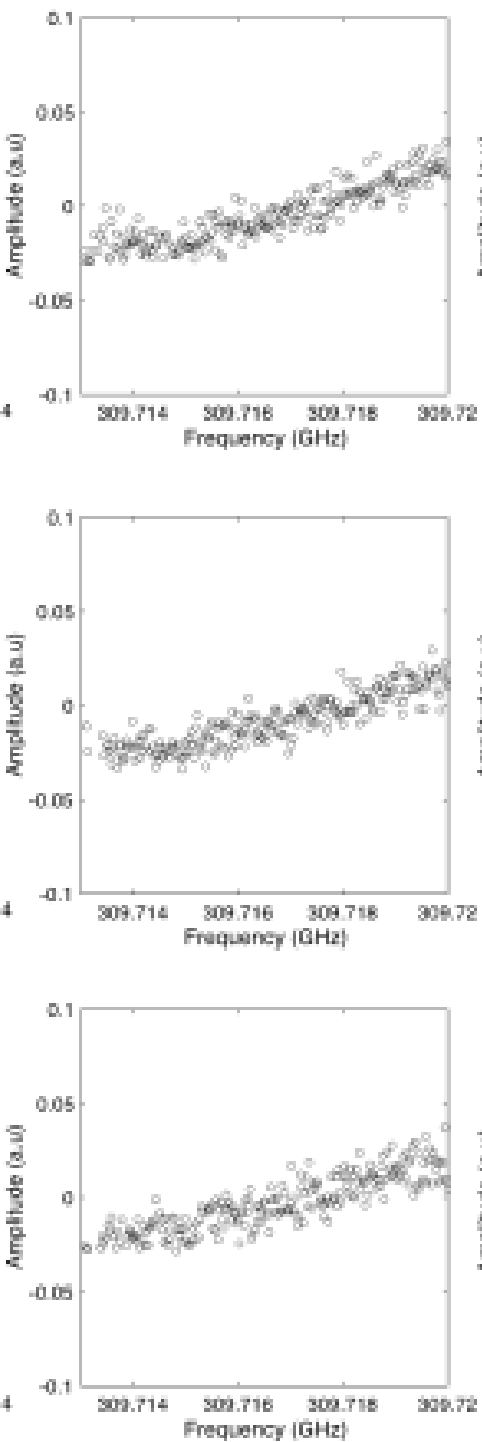

$\mathrm{NH}_{2} \mathrm{D}$
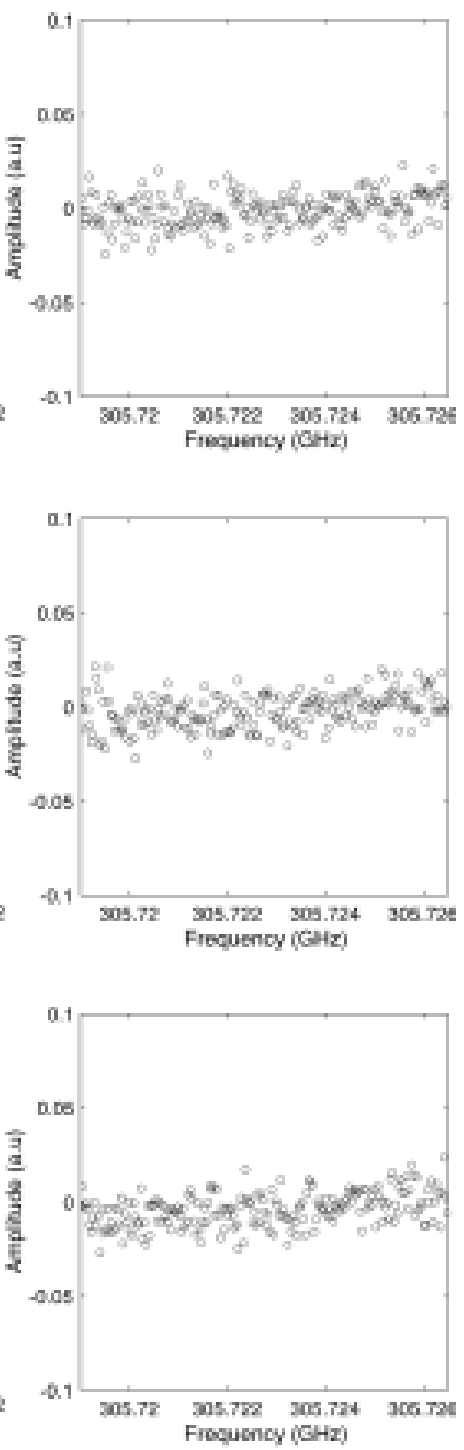

Figure S12 - Hydrolysis of MgO without TiN. The evolution of ammonia isotopologues were monitored during the hydrolysis of pure $\mathrm{MgO}$ at the end of a chemical looping cycle. No ammonia was observed over the course of 60 minutes. 
${ }^{12} \mathrm{CO}$
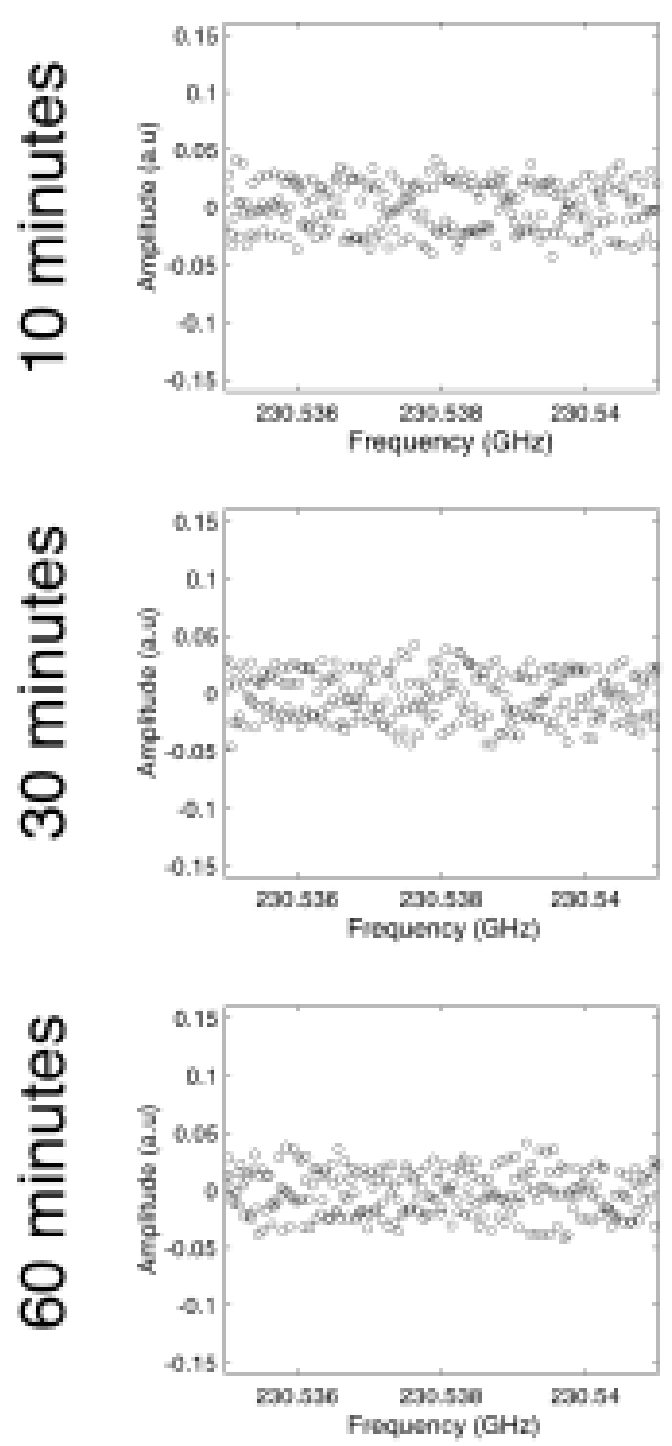

${ }^{13} \mathrm{CO}$
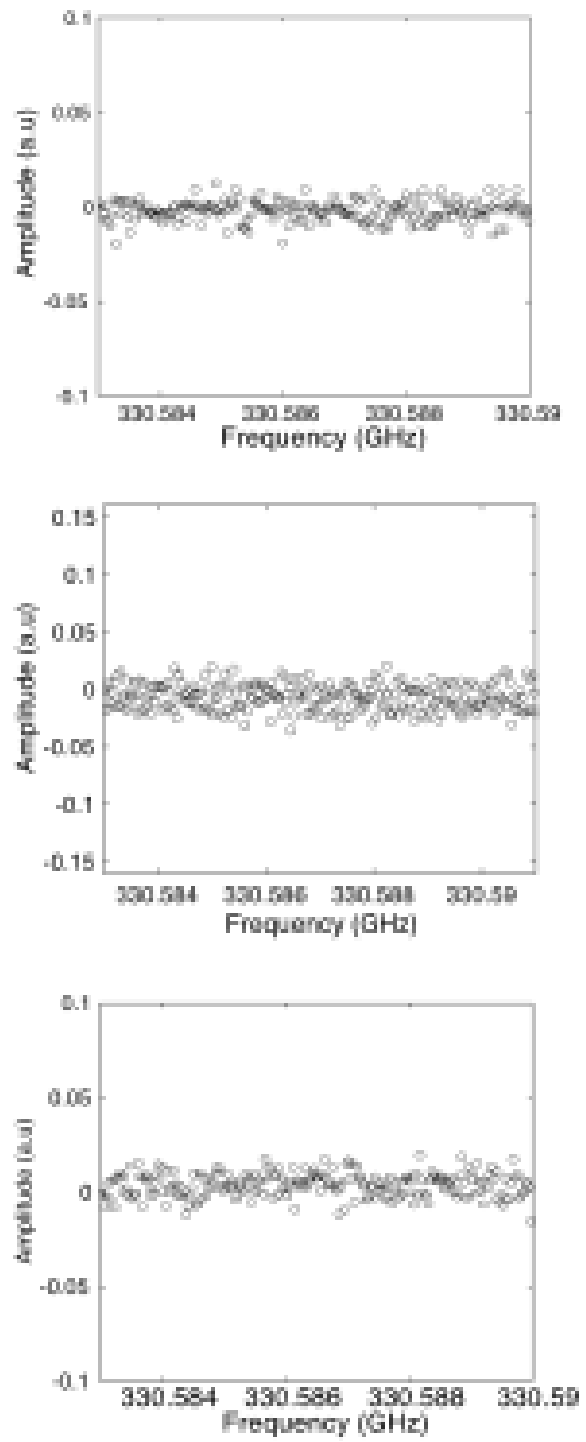

Figure S13 - Carbon monoxide evolution from pure TiN nanoparticles. A nominal pressure of 50 mTorr ${ }^{13} \mathrm{CH}_{4}$ was introduced to pure TiN nanoparticle powder under illumination at $808 \mathrm{~nm}$ and $30 \mathrm{~W} / \mathrm{cm}^{2}$ and ${ }^{12} \mathrm{CO}$ and ${ }^{13} \mathrm{CO}$ rotational transitions were monitored. No carbon monoxide evolution was observed over 60 minutes, suggesting that $\mathrm{CO}$ derives from the reduction of $\mathrm{MgO}$ at elevated temperatures. 

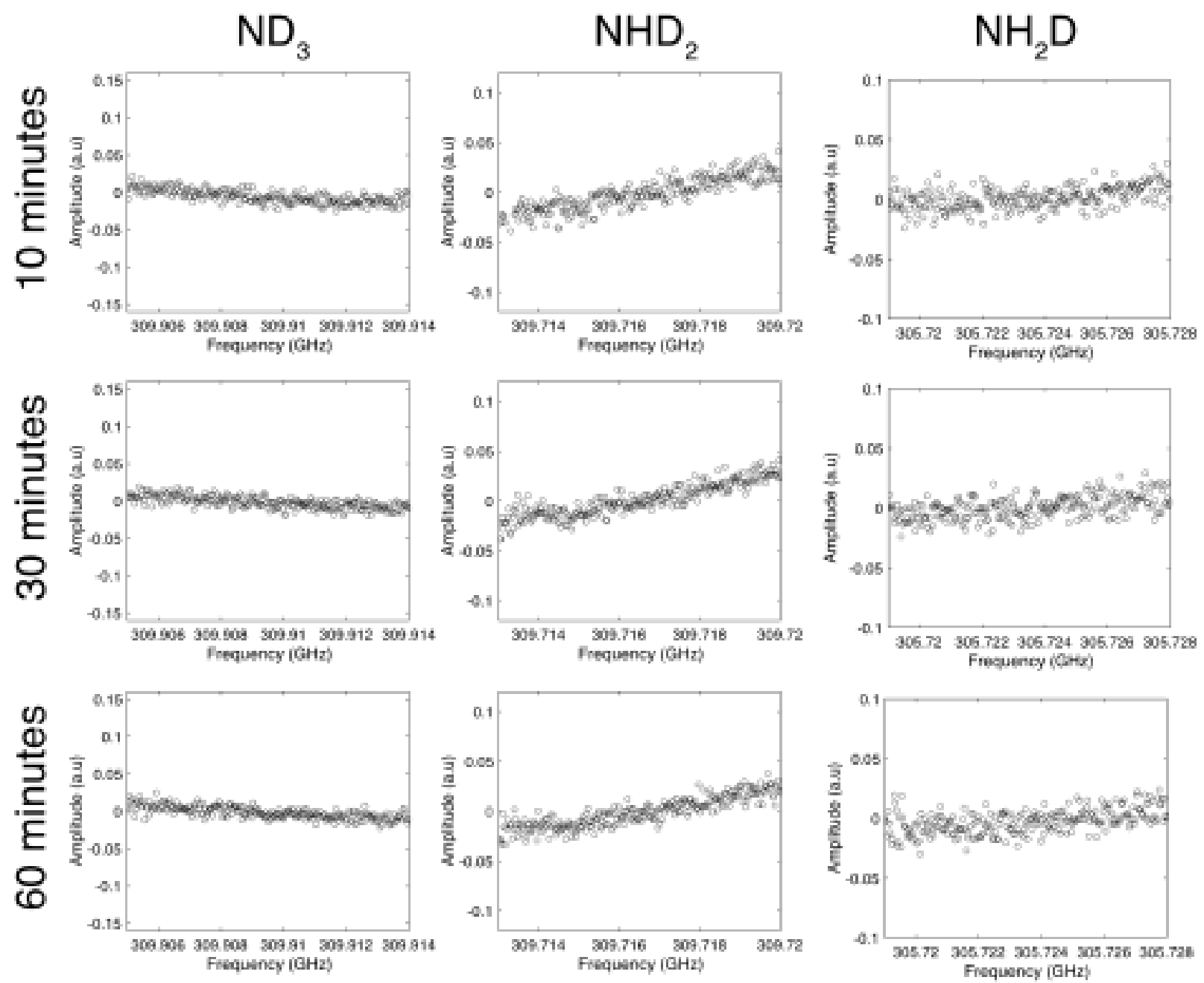

Figure S14 - Hydrolysis of pure TiN Nanoparticles. Under $808 \mathrm{~nm}$ illumination at $30 \mathrm{~W} / \mathrm{cm}^{2}$ TiN nanoparticles were exposed to $\mathrm{D}_{2} \mathrm{O}$ and isotopologues for ammonia evolution were monitored, but no hydrolysis of the TiN nanoparticles was observed over the course of 60 minutes. This can be rationalized based on an iconicity rationale, ${ }^{3}$ where the covalent $\mathrm{Ti}-\mathrm{N}$ bonds do not readily hydrolyze under the conditions present in the current study. 


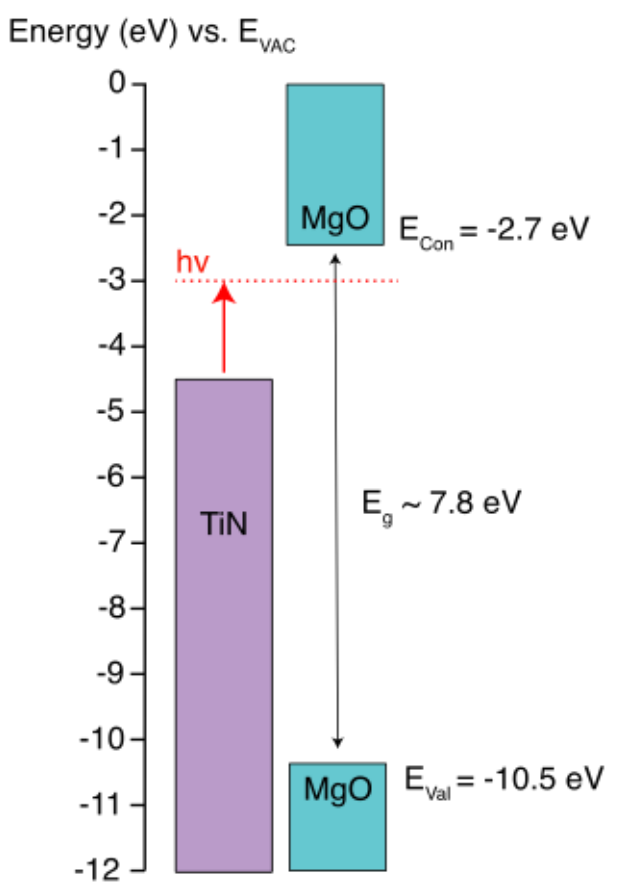

Figure S15 - Band Alignment of TiN and MgO. TiN has been reported to have a work function of $\sim 4.5 \mathrm{eV} .{ }^{5} \mathrm{MgO}$ is a wide band-gap insulator $(7.8 \mathrm{eV})$, with a valence band at $-10.5 \mathrm{eV}$ and a conduction band edge at $-2.7 \mathrm{eV} .{ }^{6}$ Therefore the valence band edge of TiN rests $1.8 \mathrm{eV}$ below $\mathrm{MgO}$. In the experiments performed in this report, all incident photons were at $808 \mathrm{~nm}(1.53 \mathrm{eV})$ so hotcarrier injection directly to valence band of $\mathrm{MgO}$ is not possible. Defect states could induce states within the band gap of $\mathrm{MgO}$ that could result in electronic contributions but no direct evidence of this possibility has been found here. Therefore, photothermal heating from TiN is the most likely mechanisms for $\mathrm{MgO}$ reduction. 
A

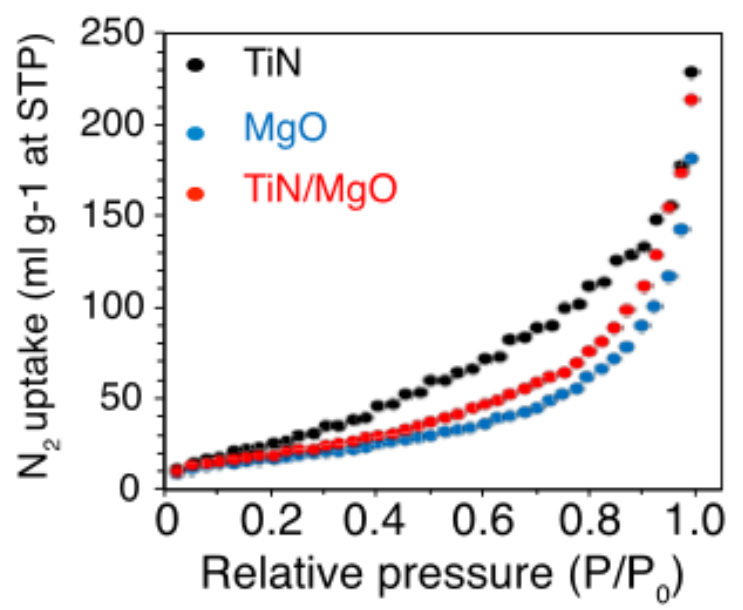

C

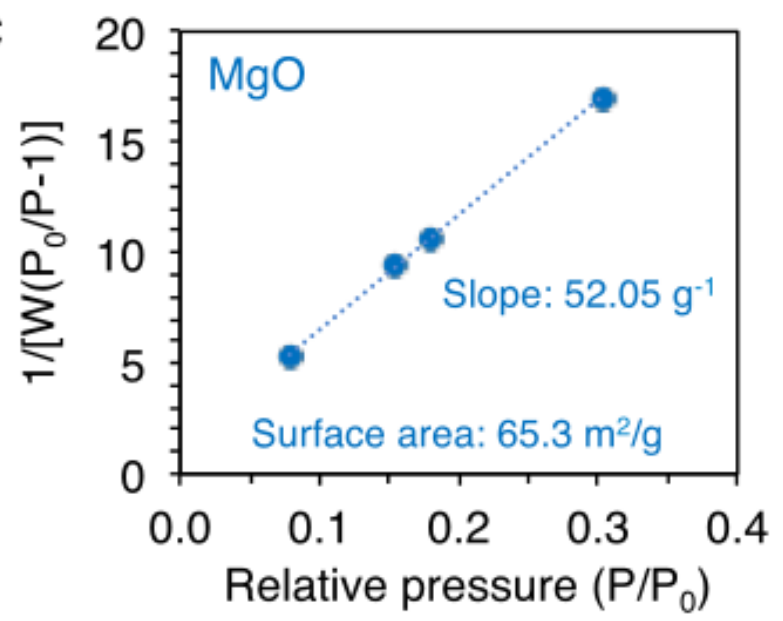

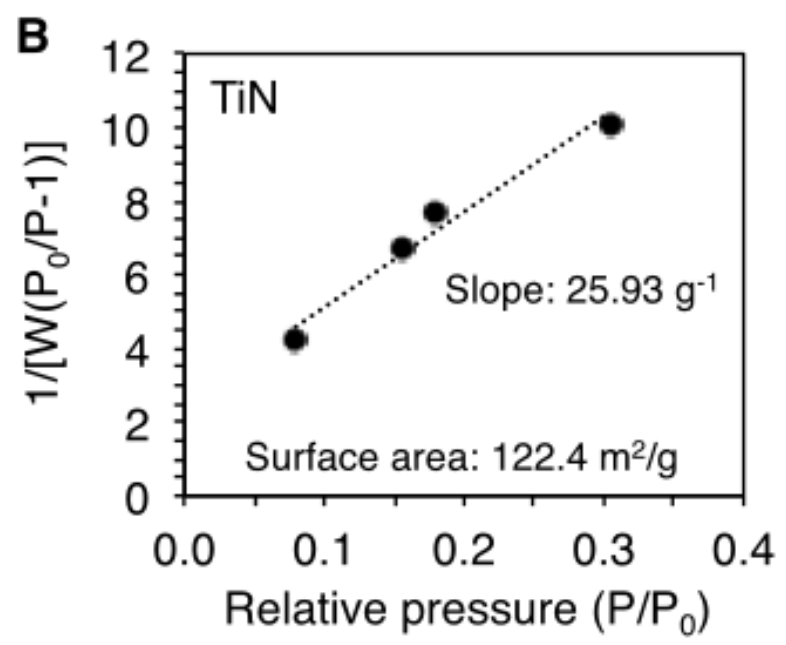

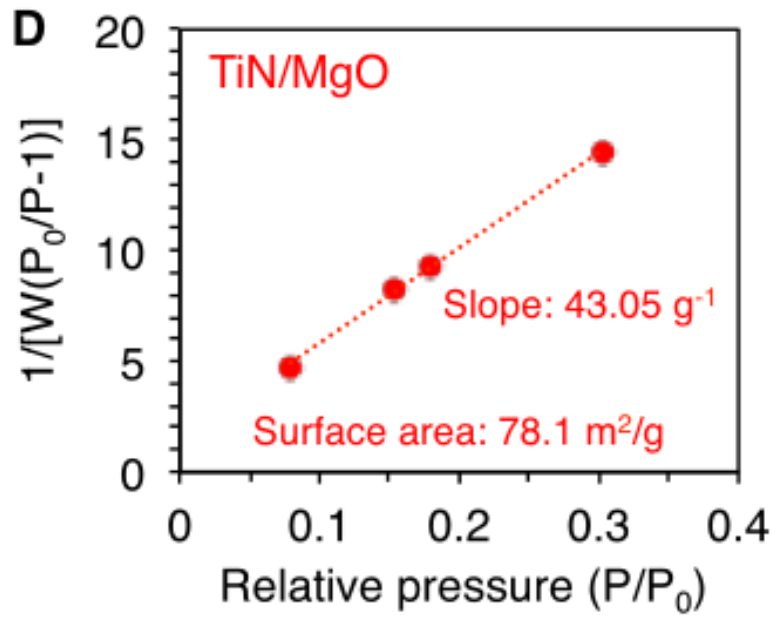

Figure $\mathrm{S} 16-\mathrm{N}_{2}$ uptake capacity and surface area measurements. (a) $\mathrm{N}_{2}$ adsorption isotherm for the $20 \mathrm{~nm} \mathrm{TiN} \mathrm{nanoparticles,} 50 \mathrm{~nm} \mathrm{MgO}$, and $20 \mathrm{wt} \% \mathrm{TiN} / \mathrm{MgO} \mathrm{NP}$ at $77 \mathrm{~K}$. STP, standard temperature and pressure. (b-d) multiple-point BET for (b) $\mathrm{TiN}$, (c) $\mathrm{MgO}$, and (d) $20 \mathrm{wt} \%$ TiN/MgO NP; where the slope where used to calculate the surface area for each compound. The calculated surface area of $78.1 \mathrm{~m}^{2} / \mathrm{g}$ for the $20 \mathrm{wt} \%$ TiN in mixture with $\mathrm{MgO}$ matches well with surface areas of $122.4 \mathrm{~m}^{2} / \mathrm{g}$ and $65.3 \mathrm{~m}^{2} / \mathrm{g}$ for the pure $\mathrm{TiN}$ and $\mathrm{MgO}$, respectively. 


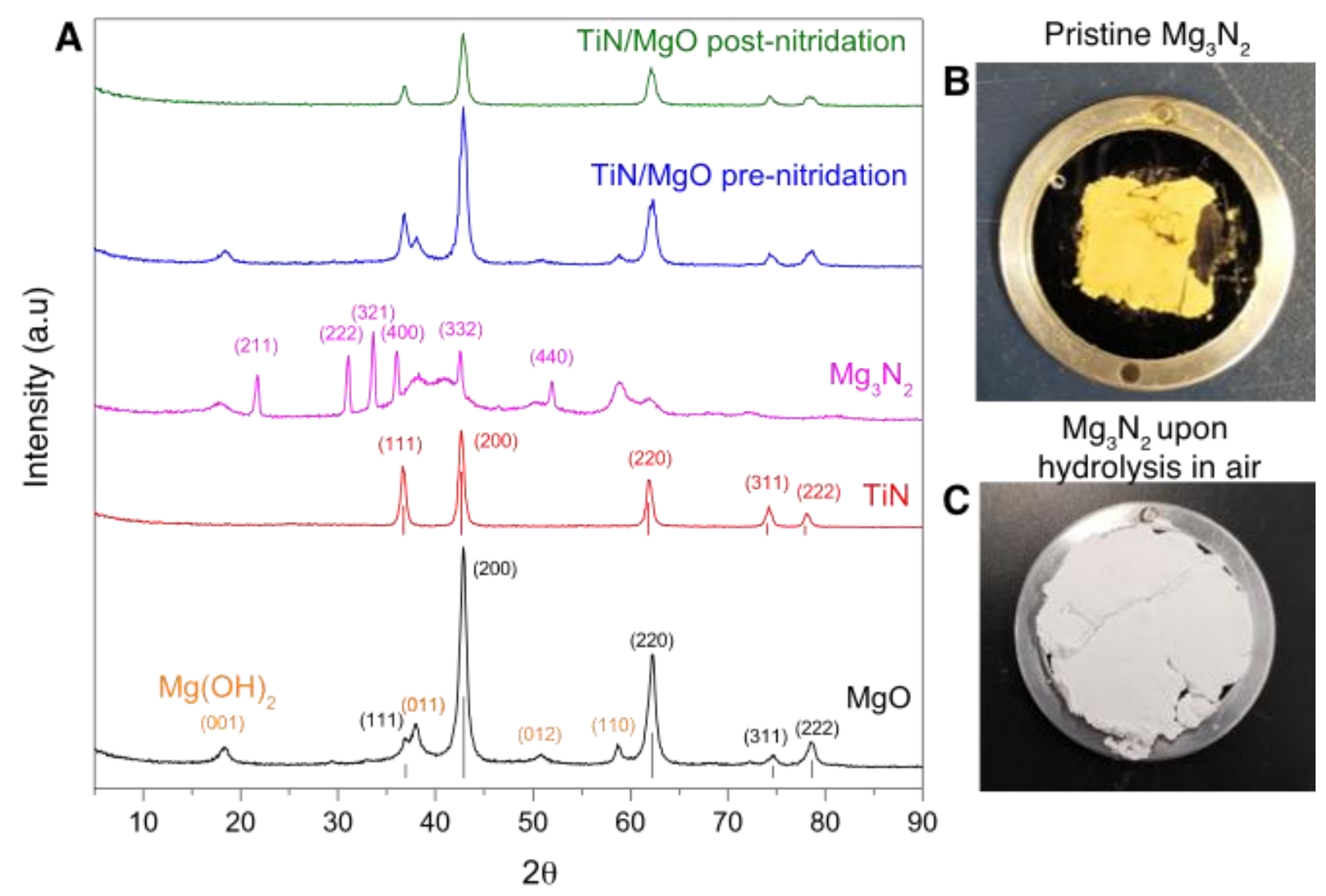

Figure S17 - Powder x-ray diffraction characterization. (a) Diffraction patterns for pristine $\mathrm{MgO}$ (black), TiN (red), $20 \mathrm{wt} \% \mathrm{TiN} / \mathrm{MgO}$ pre-nitridation, $20 \mathrm{wt} \% \mathrm{TiN} / \mathrm{MgO}$ post-nitridation, and commercial $\mathrm{Mg}_{3} \mathrm{~N}_{2}$ as a reference. Diffraction peaks were assigned using PDF\#98-000-0349 (MgO), PDF\#98-000-0130 (Mg(OH) 2 ), PDF\#98-000-0339 (TiN), and ref. ${ }^{7}$ for $\mathrm{Mg}_{3} \mathrm{~N}_{2}$. (b) Digital images of commercial $\mathrm{Mg}_{3} \mathrm{~N}_{2}$ (yellow powder) and upon hydrolysis into (c) $\mathrm{MgO} / \mathrm{Mg}(\mathrm{OH}$ ) 2 (white powder) in air during XRD measurements. Overlapping diffraction peaks of TiN and $\mathrm{MgO}$ make XRD analysis difficult to interpret and lack of environmental control within the diffractometer makes the identification of low quantities of $\mathrm{Mg}_{3} \mathrm{~N}_{2}$ in $\mathrm{TiN} / \mathrm{MgO}$ post-nitridation samples challenging. 


\section{Supplementary Tables}

Table SI. Curve fitting summary of XPS spectra for TiN/MgO Pre-Nitridation. The data presented here corresponds to Figure S9a and Table I in the main text.

\begin{tabular}{|c|c|c|c|c|c|c|c|}
\hline \multicolumn{8}{|c|}{ Pre-Nitridation } \\
\hline Position & Separation & FWHM & Height & $\begin{array}{c}\% \\
\text { Gauss }\end{array}$ & Area & \%Area & X-squared \\
\hline \multicolumn{8}{|c|}{$\operatorname{Ti} 2 p$} \\
\hline 452.82 & 0 & 1.6 & 172 & 100 & 292 & 8.83 & 1.96 \\
\hline 454.86 & 2.05 & 2.54 & 224 & 100 & 605 & 17.38 & \\
\hline 456.55 & 3.73 & 1.7 & 172 & 100 & 312 & 8.95 & \\
\hline 457.12 & 4.31 & 2.46 & 454 & 80 & 1301 & 37.35 & \\
\hline 459.76 & 6.94 & 2.21 & 108 & 100 & 254 & 7.28 & \\
\hline 462.46 & 9.64 & 2.63 & 235 & 80 & 720 & 20.66 & \\
\hline \multicolumn{8}{|c|}{ N1s } \\
\hline 394.6 & 0 & 1.8 & 101 & 68 & 224 & 100 & 1.6 \\
\hline \multicolumn{8}{|c|}{$\mathrm{Mg} 2 \mathrm{~s}$} \\
\hline 87.38 & 0 & 2.41 & 308 & 91 & 823 & 85.43 & 1.2 \\
\hline 89.35 & 1.96 & 2.38 & 49 & 74 & 140 & 14.57 & \\
\hline \multicolumn{8}{|c|}{$01 \mathrm{~s}$} \\
\hline 528.71 & 0 & 2.06 & 1718 & 85 & 4030 & 72.31 & 3.06 \\
\hline 530.66 & 1.96 & 2.35 & 577 & 85 & 1544 & 27.69 & \\
\hline
\end{tabular}


Table SII. Curve fitting summary of XPS spectra for TiN/MgO Post-Nitridation. The data presented here corresponds to Figure S9b and Table I in the main text.

\begin{tabular}{|l|c|c|c|c|c|c|c|}
\hline \multicolumn{7}{|c|}{ Post-Nitridation } \\
\hline Position & Separation & FWHM & Height & $\begin{array}{c}\text { \% } \\
\text { Gauss }\end{array}$ & Area & \%Area & X-squared \\
\hline \multicolumn{7}{|c|}{ Ti 2p } \\
\hline 452.84 & 0 & 1.52 & 676 & 100 & 1091 & 18.04 & 2.89 \\
\hline 454.76 & 1.91 & 2.19 & 610 & 100 & 1420 & 23.49 & \\
\hline 456.44 & 3.6 & 1.7 & 501 & 100 & 907 & 15 & \\
\hline 457.77 & 4.93 & 2.46 & 525 & 100 & 1373 & 22.71 & \\
\hline 459.76 & 6.91 & 2.21 & 202 & 100 & 474 & 7.84 & \\
\hline 462.15 & 9.31 & 2.63 & 279 & 100 & 782 & 12.93 & \\
\hline & & & N 1s & & \\
\hline 394.73 & 0 & 2 & 616 & 80 & 1436 & 86.6 & 3.12 \\
\hline 396.46 & 2.08 & 2.3 & 82 & 78 & 222 & 13.4 & \\
\hline
\end{tabular}




\begin{tabular}{|c|c|c|c|c|c|c|c|}
\hline \multicolumn{7}{|c|}{ Mg 2s } \\
\hline 87.14 & 0 & 2.28 & 1231 & 93 & 3093 & 96.3 & 3.7 \\
\hline 88.9 & 1.76 & 1.9 & 56 & 90 & 119 & 3.7 & \\
\hline \multicolumn{7}{|c|}{01 s } \\
\hline 528.71 & 0 & 1.96 & 4588 & 95 & 9798 & 79.6 & 3.11 \\
\hline 530.62 & 1.91 & 1.89 & 1168 & 86 & 2511 & 20.4 & \\
\hline
\end{tabular}

\section{Supporting References}

(1) Shiraishi, Y.; Shiota, S.; Kofuji, Y.; Hasimoto, M.; Chishiro, K.; Hirakawa, H.; Tanaka, S.; Ichikawa, S.; Hirai, T. Nitrogen Fixation with Water on Carbon-Nitride-Based Metal Free Photocatalysts with $0.1 \%$ Solar-to-Ammonia Energy Conversion Efficiency. ACS Appl. Energy Mater. 2018, 1, 4169 - 4177.

(2) Li, C.; Yang, W.; Liu, L.; Sun, W.; Li, Q. In Situ Growth of TiO2 on TiN Nanoparticles for Non-Noble-Metal Plasmonic Photocatalysis. RSC Adv. 2016, 6, 72659-72669.

(3) Peng, X. D.; Edwards, D. S.; Barteau, M. A. Reactions of O2 and H2O with Magnesium Nitride Films. Surf. Sci. 1988, 195, 103-114.

(4) Michalsky, R.; Pfromm, P. H. An Ionicity Rationale to Design Solid Phase Metal Nitride Reactants for Solar Ammonia Production. J. Phys. Chem. C. 2012, 116, 23243-23251.

(5) Vitale, S. A.; Kedzierski, J.; Healey, P.; Wyatt, P. W.; Keast, C. L. Work-Function-Tuned TiN Metal Gate FDSOI Transistors for Subthreshold Operation. IEEE Trans. Electron Devices 2011, 58, 419-426.

(6) Liu, Z.; Yin, Z.; Cox, C.; Bosman, M.; Qian, X.; Li, N.; Zhao, H.; Du, Y.; Li, J.; Nocera, D. G. Room Temperature Stable COx-Free $\mathrm{H}_{2}$ Production from Methanol with Magnesium Oxide Nanophotocatalysts. Sci. Adv. 2016, 2, 1-8.

(7) Trivedi, M. K.; Tallapragada, R. M.; Branton, A.; Trivedi, D.; Nayak, G.; Latiyal, O. Industrial Engineering \& Management Evaluation of Thermal and Physical Properties of Magnesium Nitride Powder: Impact of Biofield Energy Treatment. 2015, 4, 1-6. 